\title{
Design, Analysis, and Experimental Evaluation of a Double Coil Magnetorheological Fluid Damper
}

\author{
Guoliang Hu, Fengshuo Liu, Zheng Xie, and Ming Xu \\ School of Mechatronic Engineering, East China Jiaotong University, Nanchang, Jiangxi 330013, China \\ Correspondence should be addressed to Guoliang Hu; glhu2006@163.com
}

Received 25 May 2015; Revised 2 September 2015; Accepted 2 September 2015

Academic Editor: Rafał Burdzik

Copyright (C) 2016 Guoliang Hu et al. This is an open access article distributed under the Creative Commons Attribution License, which permits unrestricted use, distribution, and reproduction in any medium, provided the original work is properly cited.

\begin{abstract}
A magnetorheological (MR) damper is one of the most advanced devices used in a semiactive control system to mitigate unwanted vibration because the damping force can be controlled by changing the viscosity of the internal magnetorheological (MR) fluids. This study proposes a typical double coil MR damper where the damping force and dynamic range were derived from a quasistatic model based on the Bingham model of MR fluid. A finite element model was built to study the performance of this double coil MR damper by investigating seven different piston configurations, including the numbers and shapes of their chamfered ends. The objective function of an optimization problem was proposed and then an optimization procedure was constructed using the ANSYS parametric design language (APDL) to obtain the optimal damping performance of a double coil MR damper. Furthermore, experimental tests were also carried out, and the effects of the same direction and reverse direction of the currents on the damping forces were also analyzed. The relevant results of this analysis can easily be extended to the design of other types of MR dampers.
\end{abstract}

\section{Introduction}

The rheological properties of a magnetorheological fluid (MRF) can be continuously changed within several milliseconds by applying or removing external magnetic fields. These unique features have led to the development of many MRF-based devices such as the MR damper, MR valve, MR brake, and MR clutch. Among them, the most popular MRFbased devices are MR dampers due to their long range controllable damping force, fast adjustable response, and low energy consumption [1-4]. Till now, the MR dampers have a huge applications in automotive industry including off-road vehicles [5-7], and they are also widely used in naval gun controlling $[8,9]$, field of landing gear $[10,11]$, prosthetic knees [12,13], washing machines [14], high speed train suspension [15-17], seismic vibration control of different civil structures [18-20], and so on.

As well known that the performance of MR dampers significantly depended on the activating magnetic circuit, therefore the performance of MR dampers can be optimized by the optimal design of the activating magnetic circuit. Recently, some studies in the literature have focused on the geometric optimization of MR dampers. The results from these studies showed that damping performance of MR dampers can be significantly improved via optimal design of the magnetic circuit of the systems.

Yang et al. [21] presented an optimal design of a parallel disk valve mode MR damper with FEM method considering different structural parameters and different materials for the cylinder and cover of the MR damper, and the results show that both the material and the fluid gap are key factors for MR circuit. Zheng et al. [22] designed a novel MR damper with a multistage piston and independent input currents; the multiphysics of the novel MR damper was theoretically analysed and carried out, including electromagnetic, thermal dynamic, and flow mechanism. Zhang et al. [23] proposed the use of finite elements to improve the magnetic design of an MR damper. Khan et al. [24] used finite element software to simulate nine different configurations of the pistons for an MR damper and investigate how these configurations would affect and influence the maximum pressure drop. Ferdaus et al. [25] established 2D and 3D models of an MR damper that considered the shape of the piston, the MR fluid gap, the air gap, and the thickness of the damper's housing. The analytical results show that the single coil MR damper with linear plastic air gap, top and bottom chamfered piston 
end, and medium MR fluid gap has better performance. Parlak et al. [26] presented a method for optimizing the design of the target damper force and maximum magnetic flux density of an MR damper; this new approach used an electromagnetic analysis of the magnetic field and a CFD analysis of MR flow together to obtain the optimal value of the design parameters. Nguyen and Choi [27] presented an optimal design of a passenger vehicle MR damper that was constrained in a specific cylindrical volume and an advanced objective function that collectively included the damping force, the dynamic range, and an inductive time constant. Parlak et al. [28] investigated the geometrical optimization of an MR shock damper using the Taguchi experimental design approach by specifying four parameters (gap, flange thickness, radius of piston core, and current excitation) and by selecting the maximum dynamic range required as the target value. Parlak et al. [29] also evaluated the optimal solutions of the MR damper for the maximum dynamic range and the maximum damper force separately using the Taguchi experimental design method. Goldasz and Sapinski [30] presented and verified a mathematical model of a monotube MR shock absorber with an emphasis on leakage flow mechanisms and their impact on the damping output. In the study, the authors considered the impact of high speed losses, fluid chamber compressibility, cavitations, elastic deformation of cylinder, fluid inertia, floating piston inertia, gas chamber pressure, and Coulomb friction between damper components and the cylinder to make the model more accurate.

As mentioned above, though the magnetic optimal design methods can decrease the cost and the manufacturing period and improve the performance of the MR dampers, many factors are needed to consider in developing MR dampers to obtain optimal designs, that is, how to find significant geometrical dimensions and configurations of MR dampers to obtain maximum output mechanical performance, such as damping force or dynamic range, which makes the problem very challenging when using conventional optimization methods.

In this study, a double coil MR damper with annular gap was developed and prototyped; the damping force and dynamic range were also derived. A finite element model was built to investigate the performance of the double coil MR damper by considering seven damper pistons with different configurations. An optimization procedure was then constructed with the ANSYS parametric design language (APDL) to obtain the optimal parameters of the double coil MR damper. Finally, a series of dynamic experimental tests, especially the effects of the same direction and reverse direction of the currents on the damping forces, were also carried out.

\section{Design Considerations for the Double Coil MR Damper with Annular Gap}

2.1. Principle of the Proposed Double Coil MR Damper. Figure 1 shows schematic configuration of the proposed

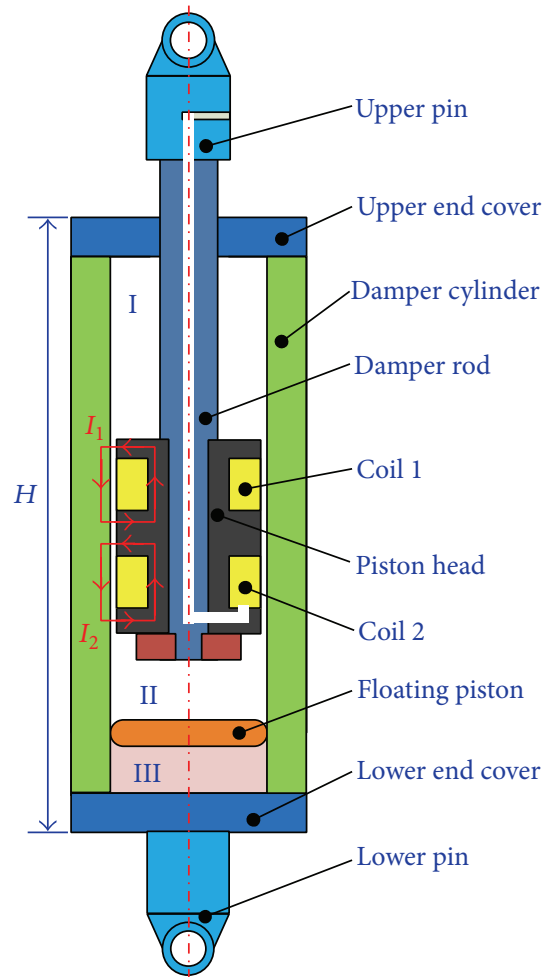

FIGURE 1: Schematic configuration of the double coil MR damper with annular gap.

double coil MR damper. There are three chambers in the damper cylinder; chamber I and chamber II are filled with MR fluid, and chamber III compensates for the changes in volume induced as the piston rod moves is filled with pressurized nitrogen gas. As the damper piston rod moves, the MR fluid flows through the annular gap between chamber I and chamber II. Moreover, there is a double coil of wire inside the piston head used for winding that is heat resistant and electrically insulated. When a direct current is applied to the double coil, a magnetic field occurs around the piston head. It is noted that the direction of the current applied onto the double coil can be the same or the reverse, which can enlarge the maximum damping force or the dynamic range to some extent.

\subsection{Magnetic Circuit and Control Model of the Double Coil} MR Damper. Figure 2 shows the simplified magnetic circuit of the double coil MR damper with an annular gap at both ends of the flanges and in the middle of the flange, where the flux lines are perpendicular to the flow direction and generate a field-dependent resistance to the fluid flow. The double coil MR damper is shaped to guide the magnetic flux axially through the damper cylinder, across the length of the flange of piston head and the gap at one end and then through the flux return and across the gap and the flange of piston head at the opposite end. The volume of fluid through which the magnetic field passes is defined as an active volume, and the MR effects only occur within the active volume. The most effective MR dampers have a high magnetic flux density passing through a large active volume, but a lot of 


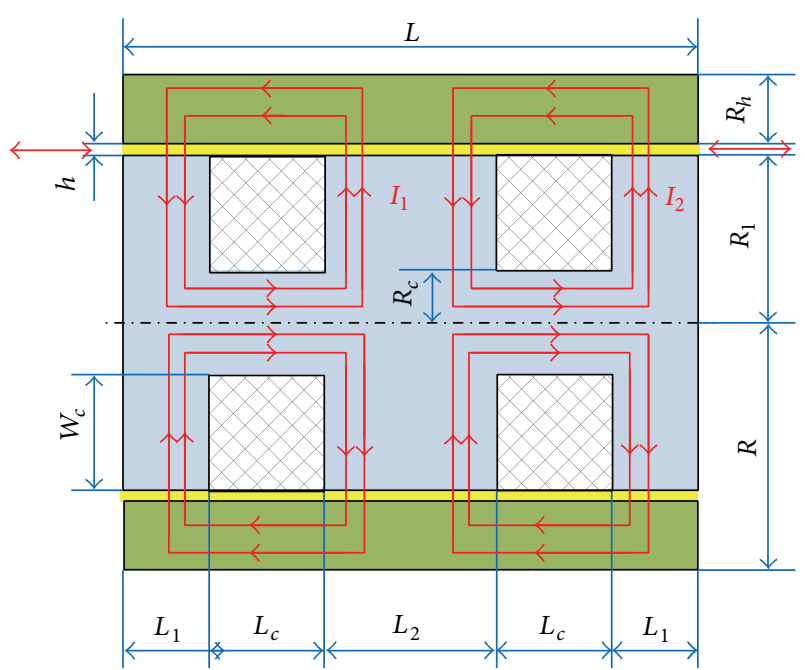

Figure 2: Simplified magnetic circuit of the double coil MR damper.

magnetic coils are needed to produce large magnetic fields. An optimized circuit would maintain a balance between the field produced and the power required by the magnetic coils.

When currents $I_{1}$ and $I_{2}$ were applied on coil 1 and coil 2, respectively, the magnetic flux density will be produced in the resistance gaps between the inner damper cylinder and the outer piston head according to the electromagnetic induction principle. The viscosity of the MR fluid in the resistance gaps will increase with the increase of the magnetic flux density. So, the damping force will be generated too. Due to the double coil design of the MR damper, the damping force can be controlled within a wide range through regulating the values and directions of the currents that applied on the double coil.

Some of the important dimensions of the double coil MR damper are also listed in Figure 2. Damper geometry is characterized by the length of the piston head $L$, the length of the end flange $L_{1}$, the length of the middle flange $L_{2}$, the length of the coil winding $L_{c}$, the thickness of the damper cylinder $R_{h}$, the width of the resistance gap $h$, the outer radius of the damper cylinder $R$, the internal radius of the piston core $R_{c}$, and the width of the coil winding $W_{c}$.

The total damping force $F$ generated by the double coil MR damper consists of three components: the fielddependent force $F_{\tau}$ due to the magnetic field, the viscous force $F_{\eta}$ due to the viscous effects, and the frictional force $F_{f}$ :

$$
F=F_{\tau}+F_{\eta}+F_{f},
$$

where

$$
\begin{aligned}
& F_{\eta}=\frac{6 \eta L q A_{p}}{\pi\left(R_{1}+0.5 h\right) h^{3}}, \\
& F_{\tau}=2 c_{1} \frac{L_{1}}{h} A_{p} \tau_{y 1} \operatorname{sgn}\left(v_{p}\right)+c_{2} \frac{L_{2}}{h} A_{p} \tau_{y 2} \operatorname{sgn}\left(v_{p}\right),
\end{aligned}
$$

where $A_{p}$ is the cross-sectional area of the piston head and $\eta$ is the plastic viscosity. $q$ is the flow rate through the double coil MR damper, and it can be calculated from the piston velocity
$v_{p}\left(q=A_{p} v_{p}\right) \cdot \tau_{y 1}$ and $\tau_{y 2}$ are the yield stresses of the MR fluid in the end flange and middle flange, respectively. $c_{1}$ and $c_{2}$ are coefficients which depended on the flow velocity profile and have a value ranging from a minimum value of 2.07 to a maximum value of 3.07. The coefficients $c_{1}$ and $c_{2}$ can be approximately estimated as follows:

$$
\begin{aligned}
& c_{1}=2.07+\frac{12 q \eta}{12 q \eta+0.8 \pi\left(R_{1}+0.5 h\right) h^{2} \tau_{y 1}}, \\
& c_{2}=2.07+\frac{12 q \eta}{12 q \eta+0.8 \pi\left(R_{1}+0.5 h\right) h^{2} \tau_{y 2}} .
\end{aligned}
$$

As shown in (1), the first term is called the controllable force because it varies with the applied field, whereas the sum of the latter two terms is referred to as the uncontrollable force because they generate a constant force according to the velocity of the damper piston.

The dynamic range $D$ is defined as the ratio of the total damping force to the uncontrollable force, and it is given by

$$
D=\frac{F_{\tau}+F_{\eta}+F_{f}}{F_{\eta}+F_{f}}=1+\frac{F_{\tau}}{F_{\eta}+F_{f}} .
$$

Here, the dynamic range $D$ was introduced to evaluate the performance of the double coil MR damper. Normally, it is better to keep the dynamic range as large as possible to maximise the effectiveness of the MR damper. The dynamic range is proportional to the shear force and is a function of the size of the gap. The width of the annular gap $h$ is inversely proportional to the controllable force, so a small gap width will increase the range of the controllable force, but when the gap $h$ is less than $0.5 \mathrm{~mm}$, the viscous force $F_{\eta}$ is much faster than the controllable force $F_{\tau}$; this reduces the dynamic range. Again when the gap becomes wider, both $F_{\tau}$ and $F_{\eta}$ fall, so finding an optimal width gap that maximises the dynamic range is very important. Moreover, parameters such as the length of the flange $L_{1}$ and $L_{2}$, the radius of the piston head $R$, the yield stress $\tau_{y 1}$ and $\tau_{y 2}$, the thickness of the damper cylinder $R_{h}$, and the internal radius of the piston core $R_{c}$ will also play an important role in searching for the optimal design.

\section{Modeling and Optimal Design of Double Coil MR Damper Using Finite Element Method}

The magnetic field in an MR damper is produced by an electromagnet. Here in the ANSYS simulation model the excitation coil is considered to be the electromagnet, and the magnetic field provided by this excitation coil is needed to energize the MR fluid. By varying the current through the excitation coil, the magnetic flux density can be varied and the MR fluid is energized accordingly. ble Coil MR Damper. The MR fluid with type of MRF-J01T 
TABLE 1: Performanceindex of MR fluid with MRF-J01T.

\begin{tabular}{lc}
\hline Project & Parameters \\
\hline Mass density & $2.65 \mathrm{~g} / \mathrm{cm}^{3}$ \\
Viscosity without magnetic field $\left(\gamma=10 / \mathrm{s}, 20^{\circ} \mathrm{C}\right)$ & $0.8 \mathrm{~Pa} \cdot \mathrm{s}$ \\
Shearstress (5000 Gs) & $>50 \mathrm{KPa}$ \\
Operational temperature range & $-40 \sim 130^{\circ} \mathrm{C}$ \\
\hline
\end{tabular}

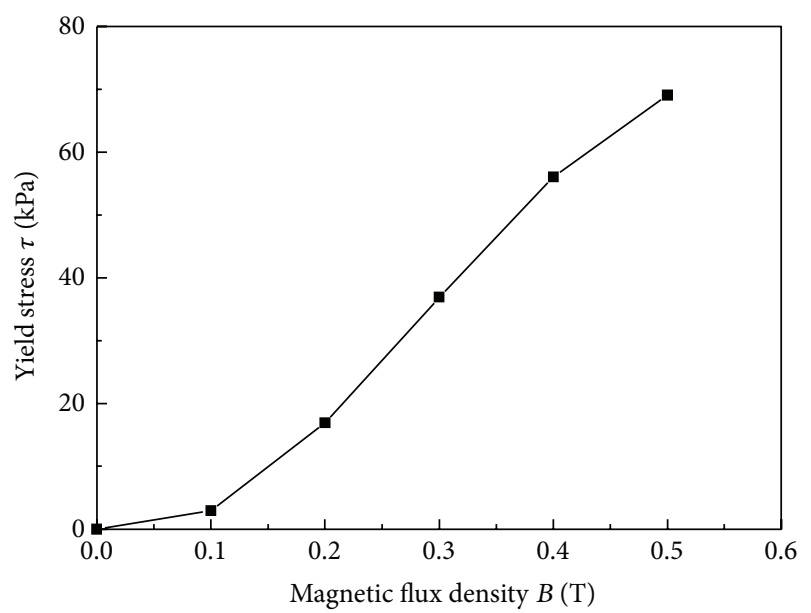

(a) Relationship of $\tau$ and $B$

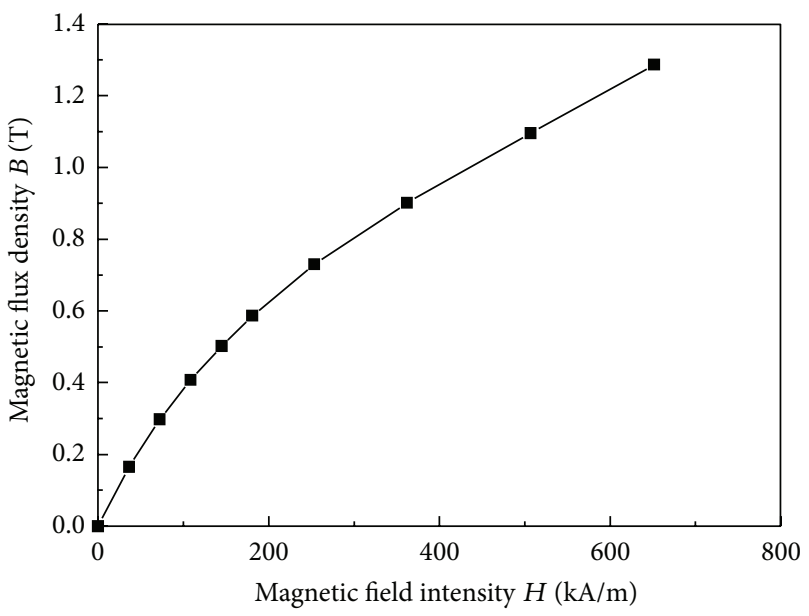

(b) Relationship of $B$ and $H$

FIgURE 3: Specification of the MR fluid type MRF-J01T.

provided by the Chongqing Instrument Material Research Institute in China was used in the following simulations and experiments. Table 1 summarizes the performance index of the MR fluid, and its field-dependent properties are shown in Figure 3.

By observing Figure 3(a), the dynamic yield stress of the MR fluid in the annular resistance gap can be approximated by

$$
\tau_{y}=\alpha_{3} \times B^{3}+\alpha_{2} \times B^{2}+\alpha_{1} \times B+\alpha_{0}
$$

where $\alpha_{0}, \alpha_{1}, \alpha_{2}$, and $\alpha_{3}$ are polynomial coefficients that are determined by the least-squares fitting of the dynamic yield

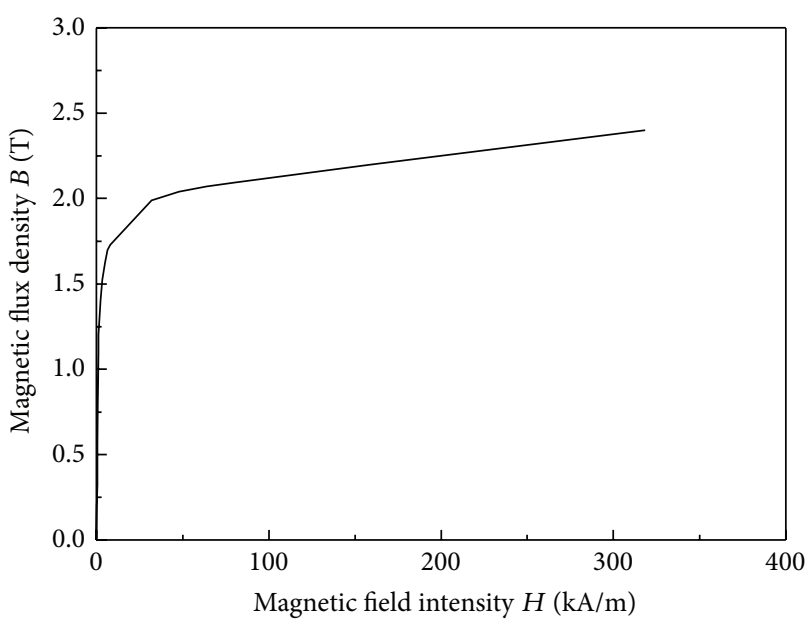

Figure 4: $B$ - $H$ curve of steel material (number 10).

stress data as a function of magnetic flux density; here $\alpha_{0}=$ $0.0182 \mathrm{kPa}, \alpha_{1}=-48.4644 \mathrm{kPa} / \mathrm{T}, \alpha_{2}=865.3901 \mathrm{kPa} / \mathrm{T}^{2}$, and $\alpha_{3}=-984.2742 \mathrm{kPa} / \mathrm{T}^{3}$.

Figure 4 shows the relationship between the magnetic flux density and the magnetic field intensity of the steel material (number 10) used in the damper cylinder and piston head, respectively.

3.2. Modeling of Double Coil MR Damper Considering Different Piston Configurations. To investigate how the shape of the damper piston affects the performance of double coil MR damper, seven models with different shaped pistons were designed, as shown in Figure 5. Model 1 piston was defined as having a plain end, Model 2 piston was defined as having each end of the piston chamfered, Model 3 piston was defined as having a radius on each end, Model 4 piston was defined as having chamfers on the top, at the bottom, and in the middle, Model 5 piston was defined as having a radius on the top, at the bottom, and in the middle, Model 6 piston was defined as having both ends chamfered, and Model 7 piston was defined as having a radius on every edge.

Table 2 and Figure 6 show the results of the magnetic flux densities between the seven different models when the applied current varies from $0.1 \mathrm{~A}$ to $1.0 \mathrm{~A}$. Here the magnetic flux densities decreased with the number of chamfers on the damper piston, the maximum density of magnetic flux appeared in Model 1, which means that this piston had the optimal geometrical shape. Moreover, the magnetic flux density in the model with a radius was greater than the chamfered model; the reason can be found in Figure 7 which shows that the distribution of magnetic flux lines along the resistance gap in Model 1 was more even than that in Models 6 and 7. The damper piston with chamfers had larger reluctances at its core because the core was larger and the cross-sectional area through which the magnetic flux passed decreased, which in turn caused the magnetic flux densities in the fluid resistance gap to decrease as well.

Figure 8 shows the dynamic range of the proposed MR damper under different piston configurations when 
TABLE 2: Magnetic flux density comparison among different models.

\begin{tabular}{lccccccc}
\hline Current $(I)$ & $B$ for Model 1 & $B$ for Model 2 & $B$ for Model 3 & $B$ for Model 4 & $B$ for Model 5 & $B$ for Model 6 & $B$ for Model 7 \\
\hline 0.1 & 0.072 & 0.070 & 0.071 & 0.066 & 0.069 & 0.063 & 0.066 \\
0.2 & 0.145 & 0.140 & 0.142 & 0.132 & 0.137 & 0.124 & 0.132 \\
0.3 & 0.212 & 0.204 & 0.208 & 0.193 & 0.200 & 0.182 & 0.234 \\
0.4 & 0.273 & 0.264 & 0.268 & 0.250 & 0.259 & 0.284 & 0.249 \\
0.5 & 0.331 & 0.319 & 0.325 & 0.302 & 0.313 & 0.330 \\
0.6 & 0.382 & 0.370 & 0.375 & 0.350 & 0.363 & 0.373 \\
0.7 & 0.428 & 0.414 & 0.421 & 0.394 & 0.408 & 0.351 \\
0.8 & 0.471 & 0.456 & 0.464 & 0.434 & 0.450 & 0.412 & 0.435 \\
0.9 & 0.510 & 0.495 & 0.502 & 0.473 & 0.489 & 0.448 & 0.475 \\
1.0 & 0.543 & 0.529 & 0.536 & 0.508 & 0.524 & 0.483 & 0.511 \\
\hline
\end{tabular}

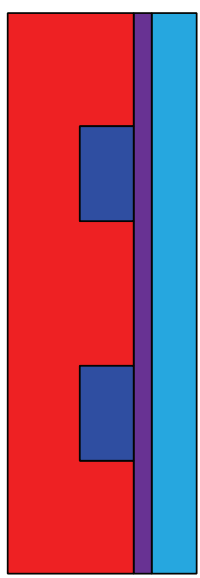

(a) Model 1

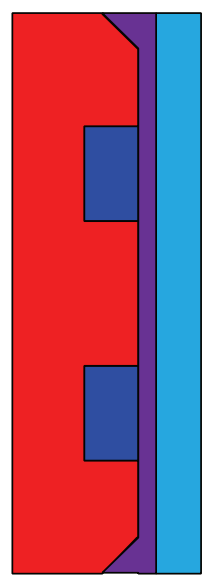

(b) Model 2

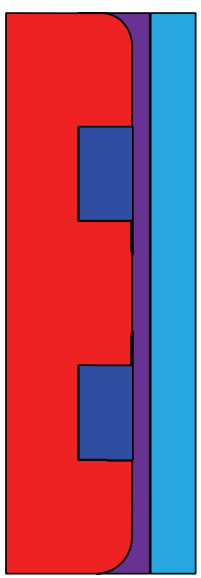

(c) Model 3

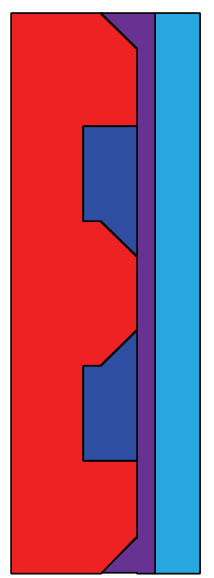

(d) Model 4

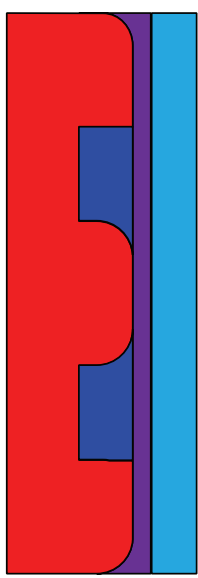

(e) Model 5

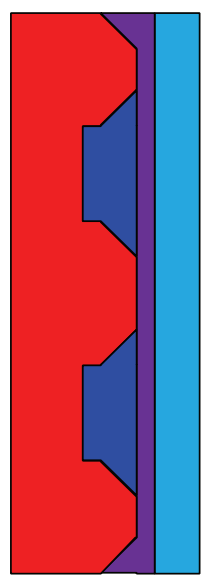

(f) Model 6

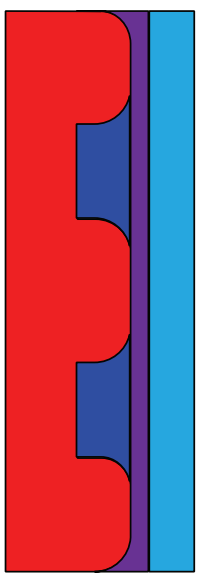

(g) Model 7

FIGURE 5: Simulation models with different piston shapes.

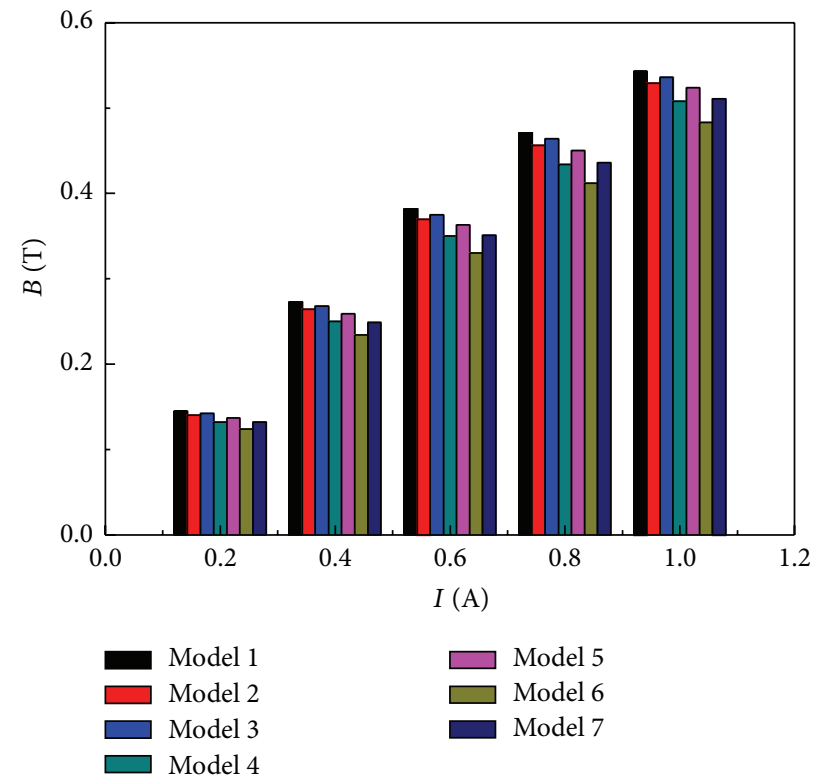

FIgURE 6: Magnetic flux density of different models.

the applied current varied from $0.1 \mathrm{~A}$ to $1.0 \mathrm{~A}$. Here the dynamic range decreased as the number of chamfers on the pistons increased, and so too did the damping performance. Moreover, the dynamic range in the model with a radius on the edges was greater than the model with chamfered edges. When the current varied from $0.1 \mathrm{~A}$ to 1.0 A, the damping force steadily increased and then stabilised when the current was close to $1.0 \mathrm{~A}$ due to the magnetic saturation of MRF in the resistance gap. From Figure 6 to Figure 8, Model 1 with square ends had the maximum $B$ value under different currents, while the damping force and dynamic range was also better in Model 1 than in the other models. So, Model 1 with the piston with square ends was selected as the optimal geometry for the proposed MR damper.

3.3. Optimal Design of Double Coil MR Damper. After determining the optimal configuration of the damper piston, the FEM using the ANSYS parametric design language (APDL) tool is used to obtain the optimal geometric dimensions of the MR damper. For vehicle suspension design, the ride comfort and the suspension travel are the two conflicting performance indices. In order to reduce the suspension travel, a high damping force is required, while considering the ride comfort, a low damping force is expected, and thus a large dynamic range is required. Considering these effects, the 


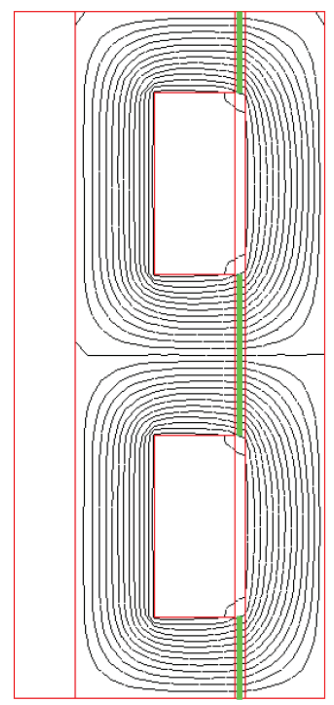

(a) Model 1

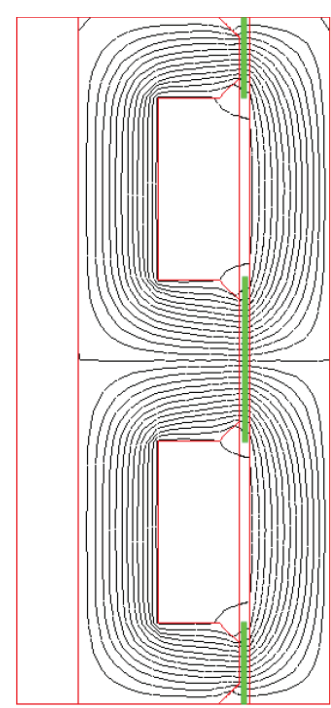

(b) Model 6

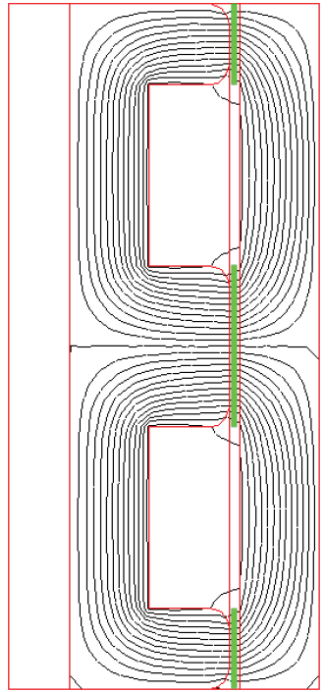

(c) Model 7

FIGURE 7: Distributions of magnetic flux lines of different models.

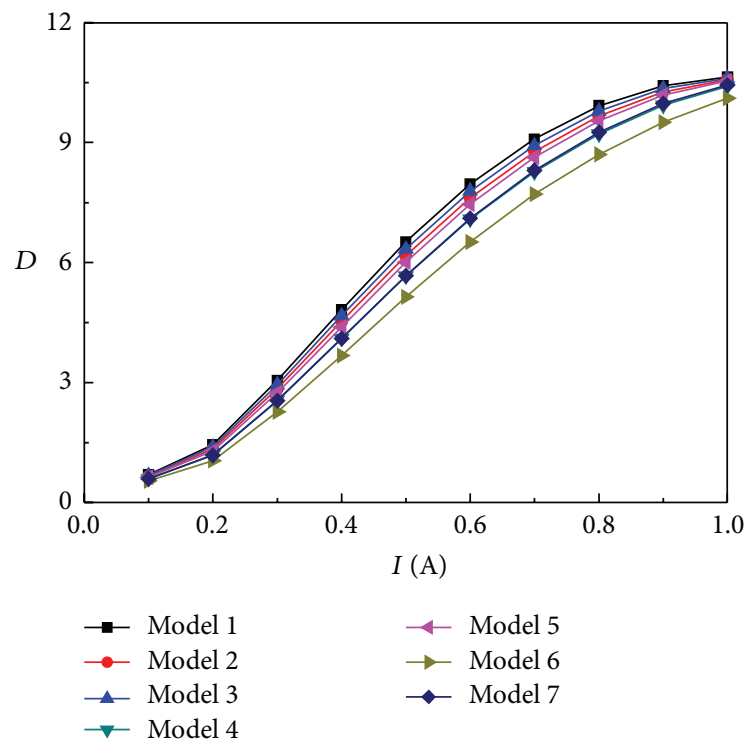

FIGURE 8: Dynamic range of MR damper under different currents.

objective function used in the optimization can be defined as

$$
\mathrm{OBJ}=\alpha_{F} \frac{F_{\tau r}}{F_{\tau}}+\alpha_{D} \frac{D_{r}}{D}+\alpha_{B} \frac{B_{r}}{B},
$$

where $F_{\tau r}, D_{r}$, and $B_{r}$ are the referenced field-dependent damping force, dynamic range, and magnetic flux density, respectively; $\alpha_{F}, \alpha_{D}$, and $\alpha_{B}$ are the weighting factors for the field-dependent damping force, dynamic range, and magnetic flux density, respectively; and the sum of $\alpha_{F}, \alpha_{D}$, and $\alpha_{B}$ is 1 . However, the values of these weighting factors are chosen depending on each specific suspension system. For uneven or unpaved road, a large damping force is required. Thus, large values of $\alpha_{F}$ and $\alpha_{B}$ are chosen. On the other hand, a large value of $\alpha_{D}$ is used in the design of suspension systems for flat roads.

In order to find the optimal solution of the double coil MR damper, an analysis log file for solving the magnetic circuit of the damper and calculating the objective function is built. In the analysis log file, the resistance length of the end flange $L_{1}$ and the internal radius of damper core $R_{c}$ are selected as the design variables (DVs), and initial values were assigned to them, respectively. The procedures to achieve the optimal design parameters using the first-order method are shown in Figure 9. Starting with initial values of the DVs, the magnetic flux density, damping force, and dynamic range are calculated by executing the log file. The ANSYS optimization tool then transforms the optimization problem with constrained DVs to an unconstrained one via penalty functions. The dimensionless, unconstrained objective function $f$ is denoted as

$$
f(x)=\frac{\mathrm{OBJ}}{\mathrm{OBJ}_{0}}+\sum_{i=1}^{n} P_{x_{i}}\left(x_{i}\right),
$$

where $\mathrm{OBJ}_{0}$ is the reference objective function value that is selected from the current group of design sets. $P_{x i}$ is the exterior penalty function for the design variable $x_{i}$. For the initial iteration $(j=0)$, the search direction of DVs is assumed to be the negative of the gradient of the unconstrained objective function, and a combination of a golden-section algorithm and local quadratic fitting techniques are used to calculate new values of DVs. If convergence occurs, the values of the DVs at this iteration are the optimum. If not, subsequent iterations will be performed. In the subsequent iterations, the procedures are similar to those of the initial iteration except that the direction vectors are calculated according to the Polak-Ribiere recursion formula [27]. Thus, each iteration 


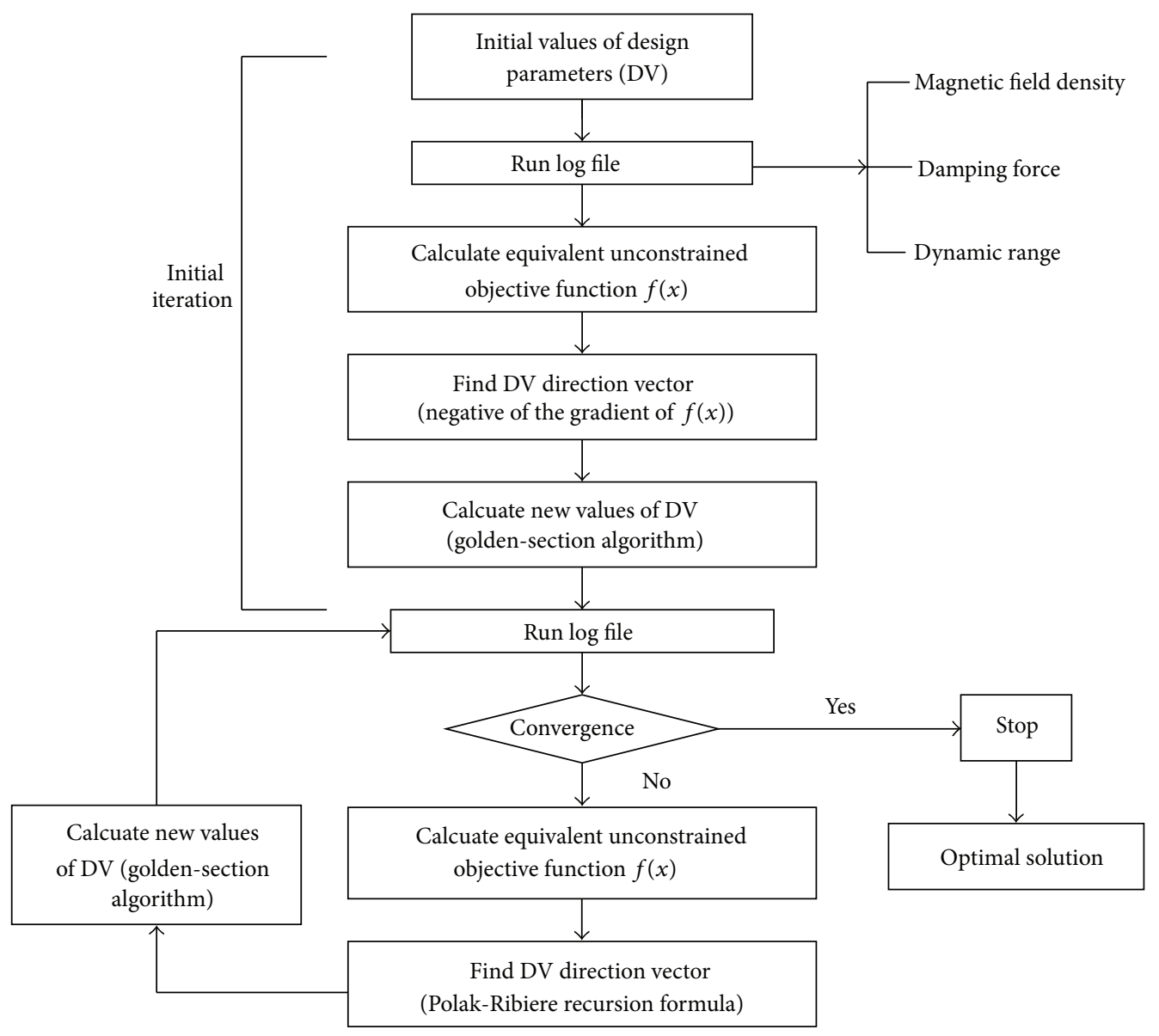

FIGURE 9: Flow chart for optimal design of the double coil MR damper.

is composed of a number of subiterations that include search direction and gradient computations.

Figures 10 and 11 show the results of magnetic flux density and damping force between the initial design and optimal design, respectively. It is obviously seen that the magnetic flux density and the damping force with an optimal design were greater than the initial design, although the difference between both of them improved significantly when the applied current exceeded $0.5 \mathrm{~A}$.

\section{Experimental Evaluation of Double Coil MR Damper}

4.1. Prototyping of the Double Coil MR Damper and the Test Rig Setup. Figure 12 is the prototype of the proposed double coil MR damper. Here, the damper piston with square ends was manufactured for the piston head. And Table 3 lists some parameters of the damper.

Figure 13 shows the test rig for the damping performance of the proposed double coil MR damper. The INSTRON 8801 test machine was used to supply the external frequency and displacement amplitude; and two power supplies were adopted to supply currents on coil 1 and coil 2, respectively; the control monitor was used to display and save the data of the damping forces.
TABLE 3: Physical dimensions of the proposed double coil MR damper.

\begin{tabular}{lccc}
\hline Parameters & Symbol & $\begin{array}{c}\text { Initial } \\
\text { value } \\
(\mathrm{mm})\end{array}$ & $\begin{array}{c}\text { Optimal } \\
\text { value }(\mathrm{mm})\end{array}$ \\
\hline Total length of damper cylinder & $H$ & 235 & 235 \\
Maximum stroke of the damper & $S$ & 40 & 40 \\
Resistance gap & $h$ & 1 & 1 \\
Outer radius of damper cylinder & $R$ & 30 & 31 \\
Internal radius of the piston core & $R_{c}$ & 13 & 14 \\
Length of the piston head $L$ & $L$ & 80 & 80 \\
Thickness of the damper cylinder & $R_{h}$ & 8 & 8 \\
Length of the end flange & $L_{1}$ & 10 & 11 \\
Length of the middle flange & $L_{2}$ & 20 & 22 \\
Length of the coil winding & $L_{c}$ & 20 & 18 \\
Width of the coil winding & $W_{c}$ & 9 & 8 \\
\hline
\end{tabular}

4.2. Damping Force under the Same Direction Currents Applied on the Double Coil. Figure 14 shows the damping force of the double coil MR damper under the different displacement amplitudes and different currents with the same direction. 


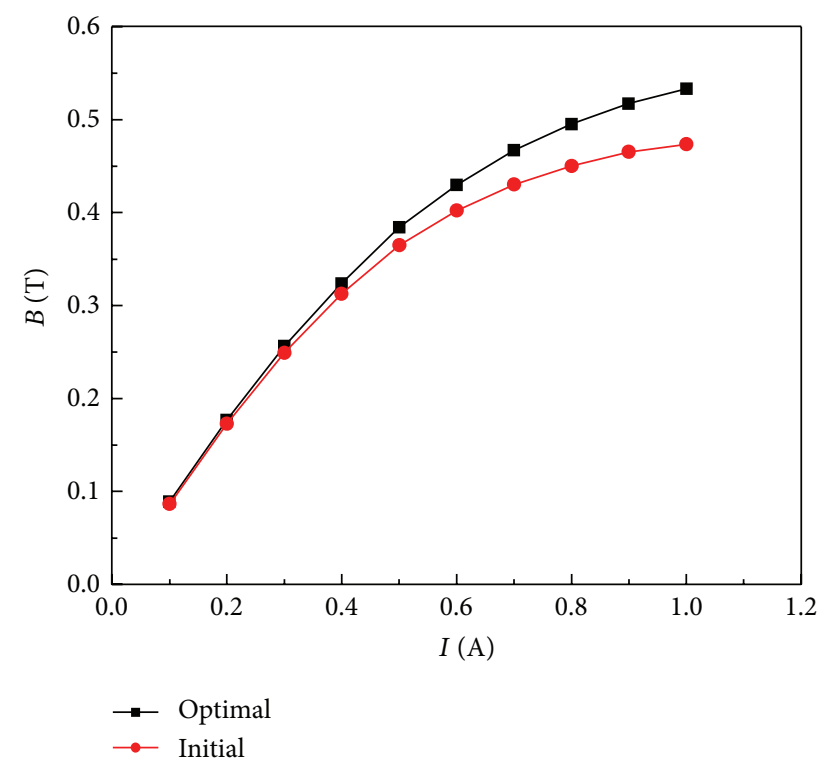

Figure 10: Comparison of magnetic flux density between initial design and optimal design.

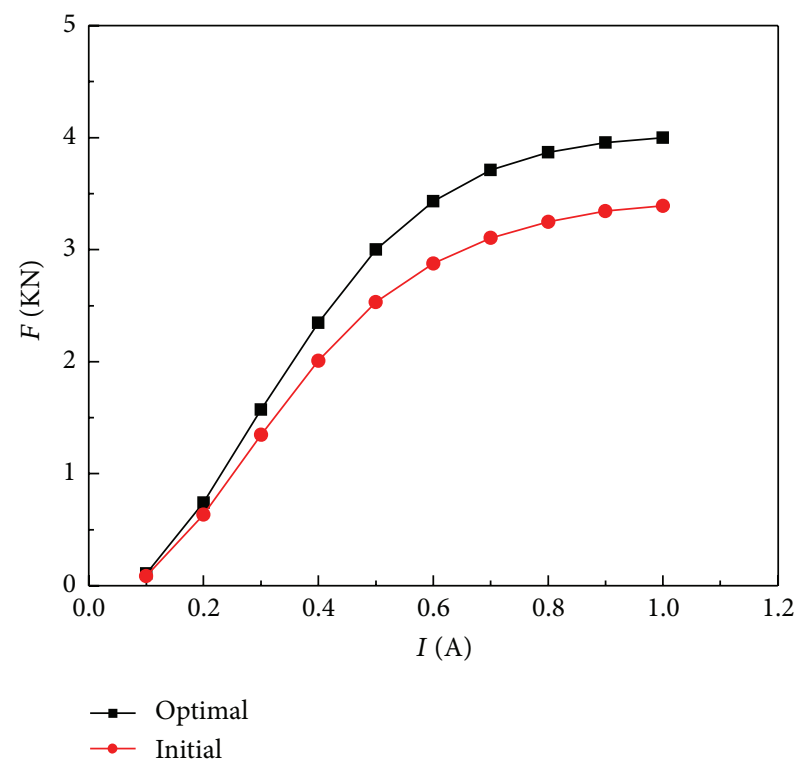

FIGURE 11: Comparison of damping force between initial design and optimal design.

Here, the test machine was set at a sinusoidal loading with a frequency of $0.5 \mathrm{~Hz}$ and displacement amplitude of $2.5 \mathrm{~mm}$ and $5.0 \mathrm{~mm}$, respectively. It can be seen that the viscous damping force equals about $100 \mathrm{~N}$ when the applied currents $I_{1}$ and $I_{2}$ are zero, and the maximum damping force can reach $220 \mathrm{~N}$ when the applied currents $I_{1}$ and $I_{2}$ are $0.25 \mathrm{~A}$. In addition, the damping force with displacement amplitude of $5.0 \mathrm{~mm}$ is greater than that of $2.5 \mathrm{~mm}$, and the damping force increases to $50 \mathrm{~N}$, which denotes that the viscous damping force is affected by the displacement amplitude.

Figure 15 shows the damping force of the double coil MR damper under the different loading frequencies and

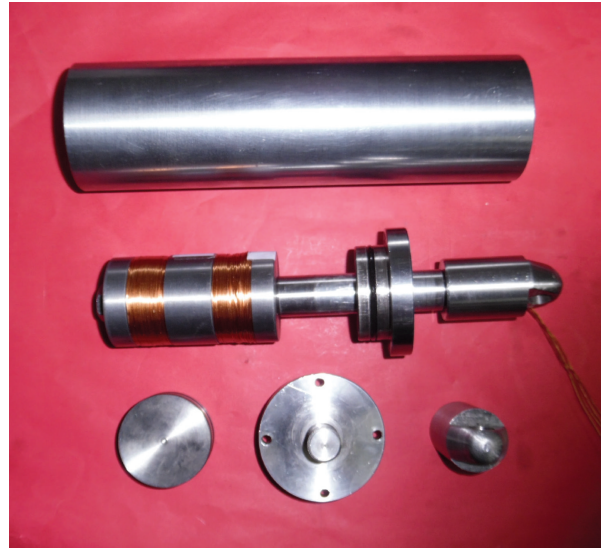

(a) Parts

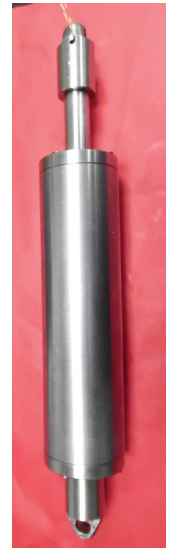

(b) Assembly
FIGURE 12: Prototype of the proposed double coil MR damper.

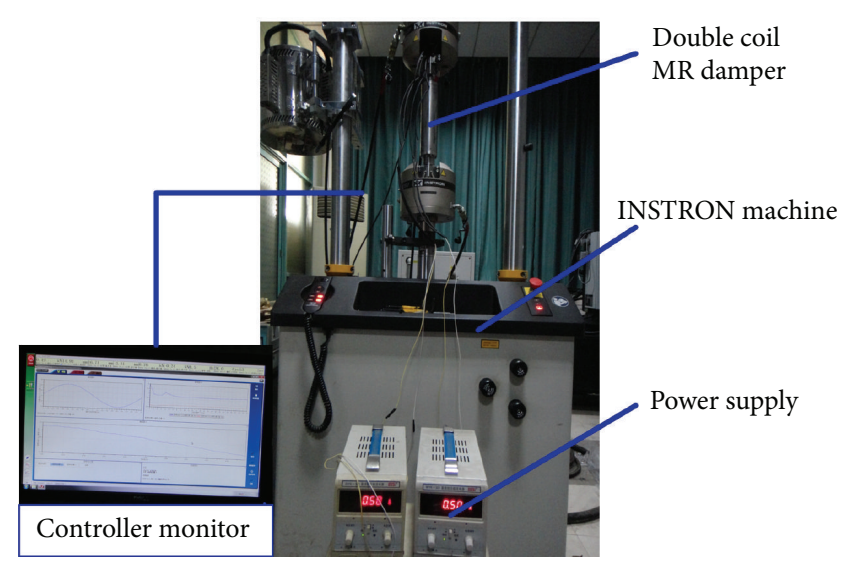

FIGURE 13: Experimental test rig for the double coil MR damper.

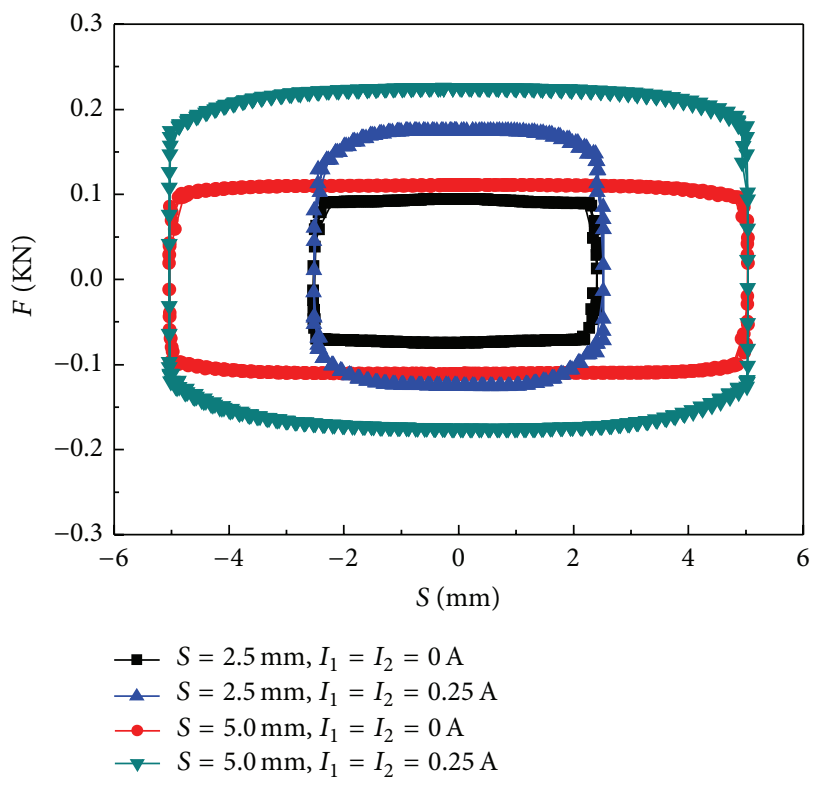

FIGURE 14: Damping force under different currents and different displacements. 


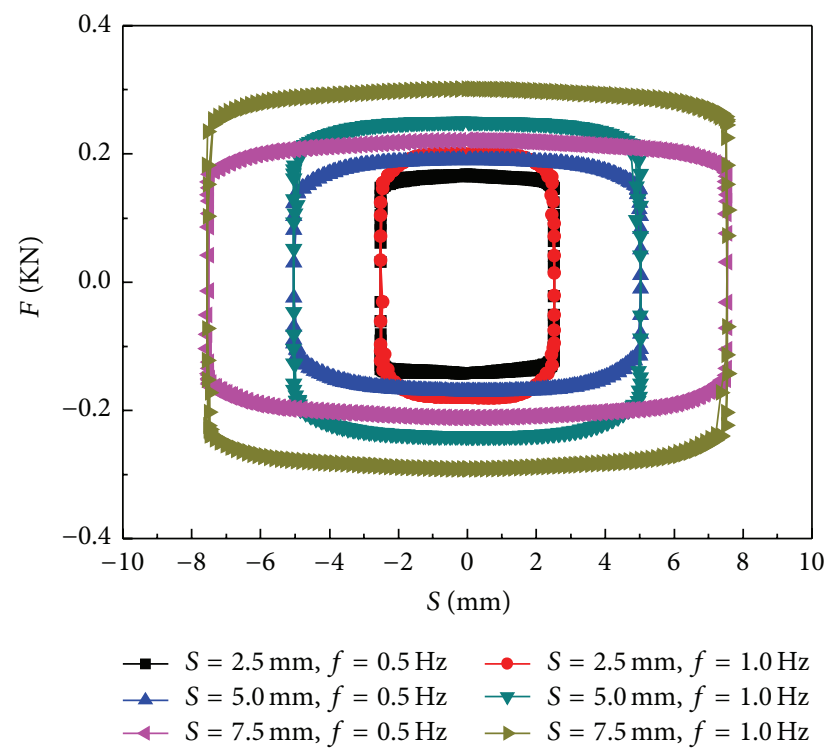

FIGURE 15: Damping force under different frequencies and different displacements.

different displacement amplitudes. Here, the test machine was set at a sinusoidal loading with a frequency of $0.5 \mathrm{~Hz}$ and $1.0 \mathrm{~Hz}$, respectively; and displacement amplitudes of $2.5 \mathrm{~mm}$, $5.0 \mathrm{~mm}$, and $7.5 \mathrm{~mm}$ were also loaded separately. Meanwhile, the applied currents $I_{1}$ and $I_{2}$ in the double coil were applied in the same direction, and the value is $0.5 \mathrm{~A}$. As shown in the figure, the greater the loading frequency is, the bigger the damping force is under the same displacement amplitude. Furthermore, the greater the displacement amplitude is, the bigger the damping force is under the same loading frequency.

4.3. Damping Force under the Reverse Direction Currents Applied on the Double Coil. Figure 16 shows the damping force under different amplitude displacements from $2.5 \mathrm{~mm}$ to $7.5 \mathrm{~mm}$. Here, the test machine was set at a sinusoidal loading with a frequency of $1.0 \mathrm{~Hz}$, and the applied currents $I_{1}$ and $I_{2}$ in the double coils were applied the reverse direction with a value of $0.7 \mathrm{~A}$. Observing Figure 16, the damping force increased with the increasing of the displacement amplitude, and the maximum damping force reaches $0.7 \mathrm{KN}$ at the displacement amplitude of $7.5 \mathrm{~mm}$.

Figure 17 shows the damping force under the applied current changed from $0 \mathrm{~A}$ to $1.0 \mathrm{~A}$. Here, the test machine was set at a sinusoidal loading with displacement amplitude of $10 \mathrm{~mm}$ and a frequency of $1.0 \mathrm{~Hz}$, while the applied currents $I_{1}$ and $I_{2}$ in the double coils were applied in the reverse direction. As expected, the damping force increased from $0.33 \mathrm{KN}$ at $0 \mathrm{~A}$ to $1.21 \mathrm{KN}$ at $1.0 \mathrm{~A}$, and the dynamic range nearly equals 4 .

Figure 18 shows the comparison of simulation results and experimental results of the damping force at the applied current of $1.0 \mathrm{~A}$. It can be seen that the maximum simulated damping force is about $4.0 \mathrm{KN}$, while the maximum experimental damping force is only $1.21 \mathrm{KN}$. The deviation is a little

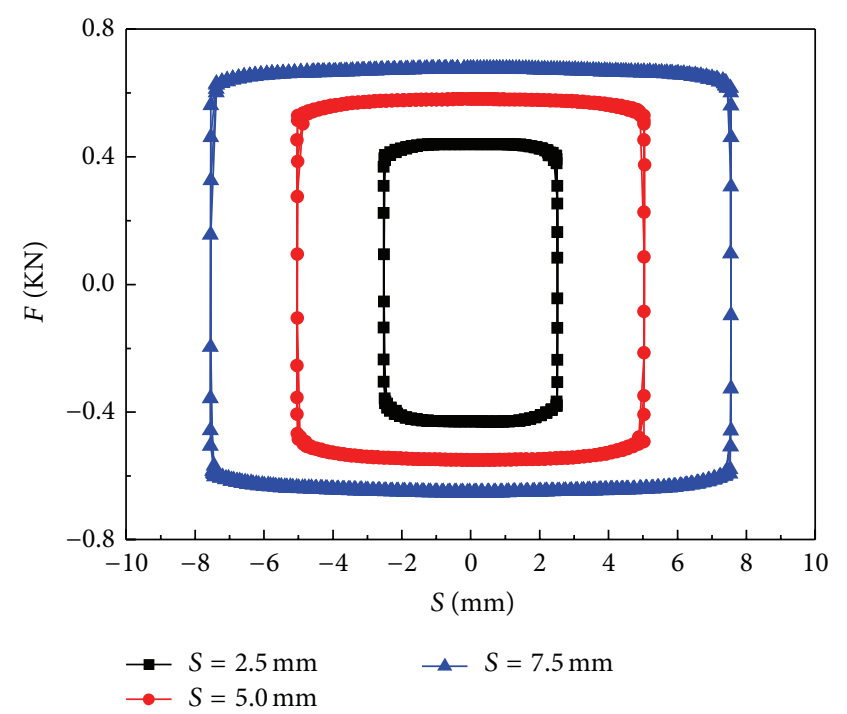

FIGURE 16: Damping force under different displacements.

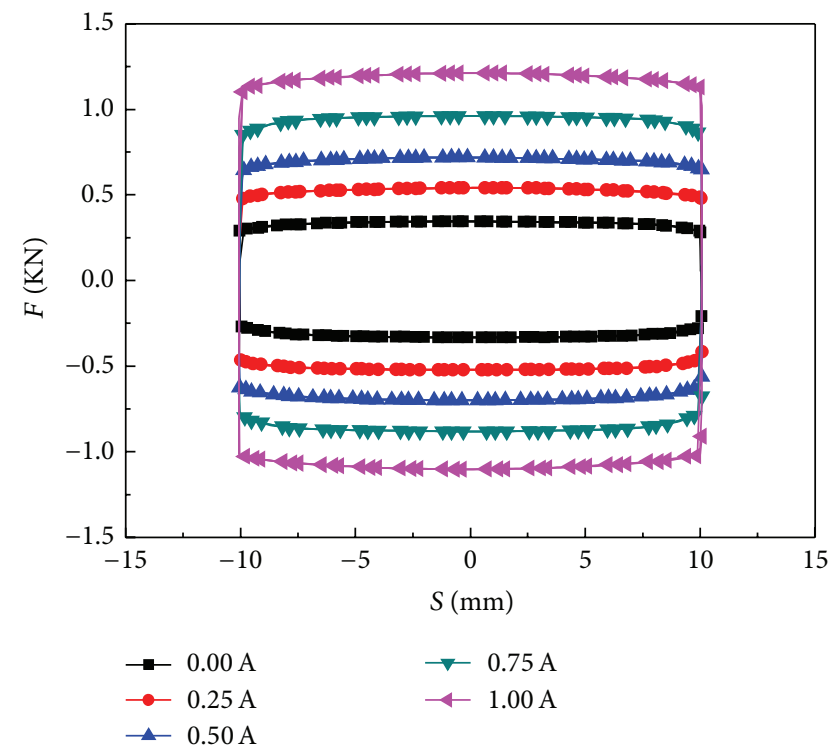

FIgURE 17: Damping force under different applied currents.

big though the trend is the same. The reason may be the thickening effect of the used MR fluid, while the Bingham fluid model used in the simulations did not consider this effect. Another possible reason may be the enhanced yield stress phenomenon process which occurs when several single chain structures of magnetic particles join together and form a thick column, which make the saturated yield stress value in the simulation bigger than the experimental conditions $[31,32]$.

Figure 19 shows the change in the damping force under different displacement amplitudes and applied current directions. Here, the test machine was set at sinusoidal loading with a frequency of $0.5 \mathrm{~Hz}$ and displacement amplitude of $5.0 \mathrm{~mm}$ and $7.5 \mathrm{~mm}$, respectively. The applied currents $I_{1}$ and $I_{2}$ in the double coils were set to $0.5 \mathrm{~A}$ with the same direction 


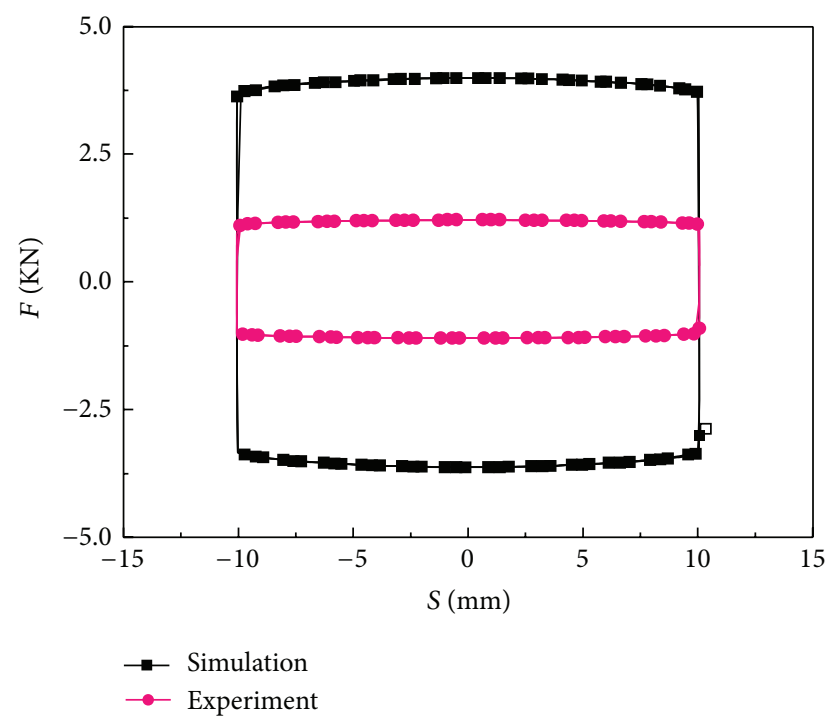

FIGURE 18: Comparison of simulated damping force and experimental damping force at the applied current of $1.0 \mathrm{~A}$.

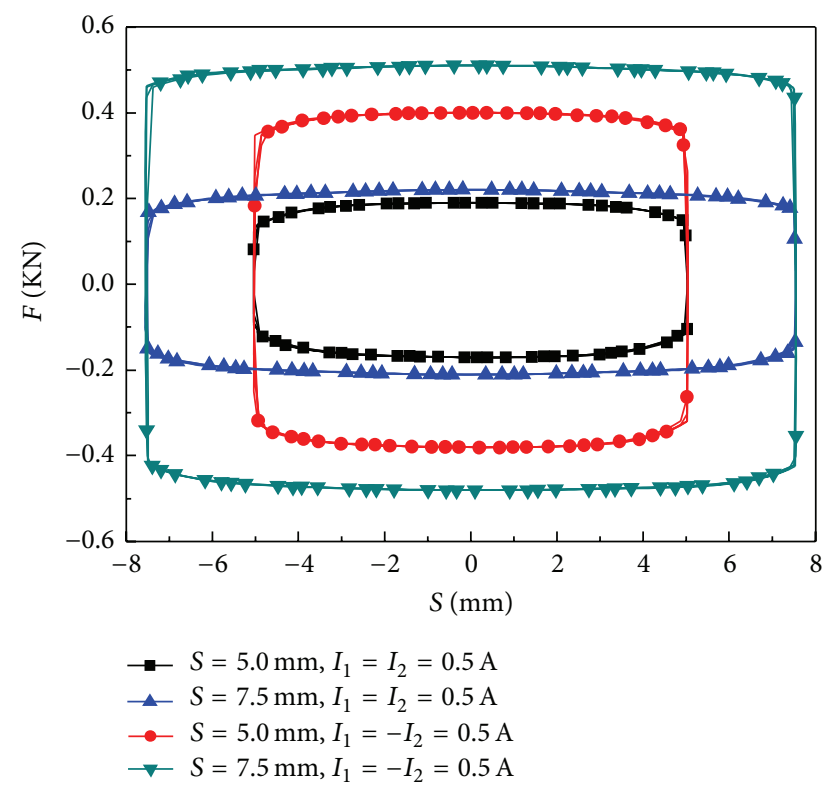

FIGURE 19: Damping forces under different displacements and different current directions.

and reverse direction, respectively. The figure shows that the damping forces with the currents in a reverse direction were much greater than those currents in the same direction. Moreover, the damping force increased as the displacement amplitude increased because the increased velocity of the damper led to an increase in the viscous damping force in (2), so the damping force also increased too.

\subsection{Damping Force under Current Applied on One of the Coils.} Figure 20 shows the change of the damping force under the varied applied current $I_{2}$ and the fixed applied current $I_{1}$, and Figure 21 shows the change of the damping force under the

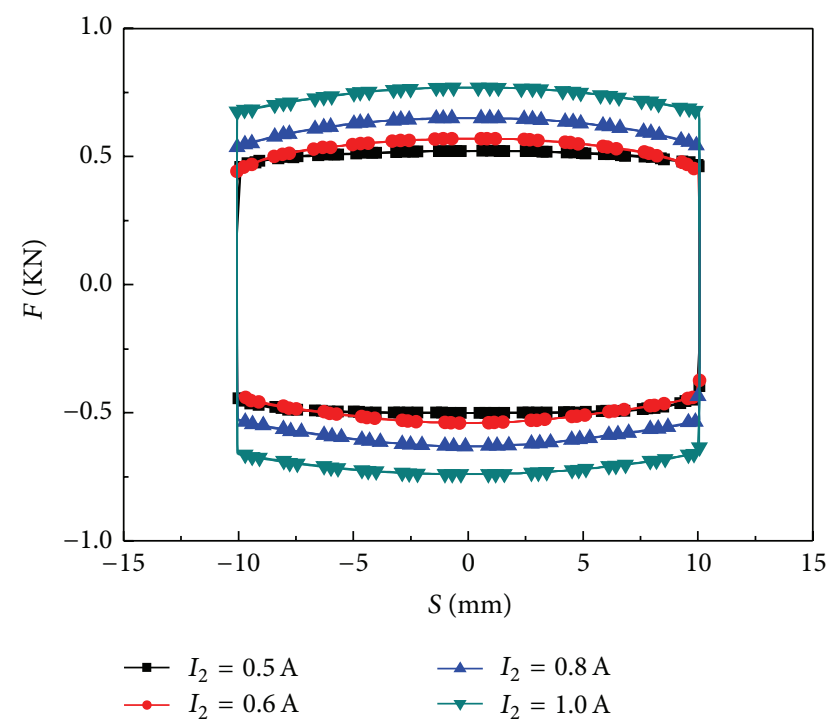

FIGURE 20: Damping force under different currents in the double $\operatorname{coil}\left(I_{1}=0.5 \mathrm{~A}\right)$.

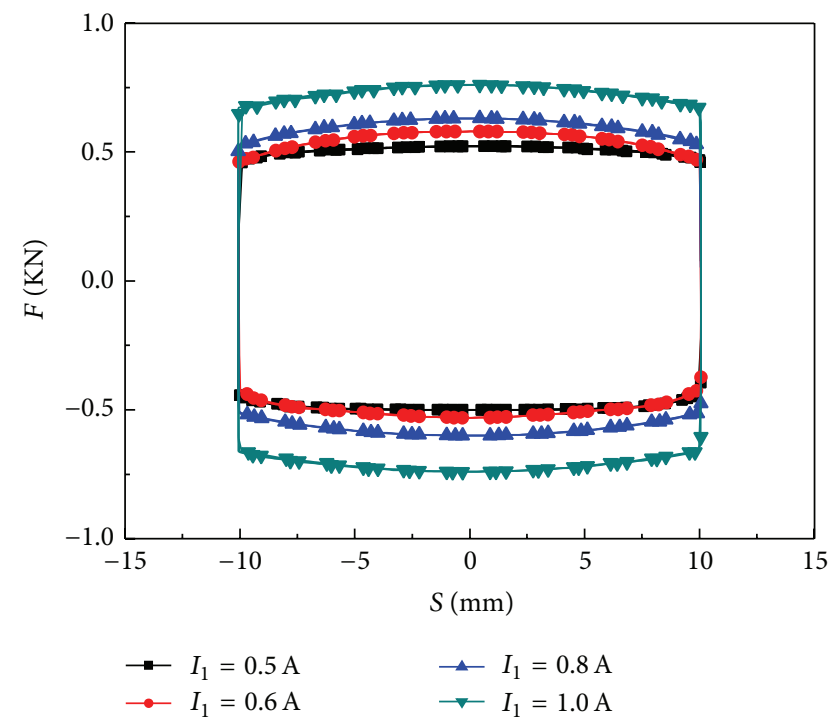

FIGURE 21: Damping force under different currents in the double coil $\left(I_{2}=0.5 \mathrm{~A}\right)$.

varied applied current $I_{1}$ and the fixed applied current $I_{2}$. Here, the test machine was set at a sinusoidal loading with amplitude displacement of $10 \mathrm{~mm}$ and a frequency of $1.0 \mathrm{~Hz}$. As shown in both figures, the damping force increased with the increase of the applied currents $I_{1}$ and $I_{2}$, respectively, though the other exciting coil's applied current was fixed. Furthermore, the damping force under the fixed current $I_{1}$ equals that under the fixed current $I_{2}$ when the total applied current is of the same value.

\section{Conclusions}

A double coil MR damper with annular gap was proposed; the damping force and dynamic range were also derived. A 
finite element model was built to investigate the performance of the proposed double coil MR damper while considering pistons with different configurations; the simulation results showed that the piston with square ends had a better damping performance. Meanwhile, an optimization procedure was constructed to obtain the optimal damping performance of the double coil MR damper. Further, an experimental analysis was also carried out to verify the damping performance of the proposed double coil MR damper.

\section{Conflict of Interests}

The authors declare that there is no conflict of interests regarding the publication of this paper.

\section{Acknowledgments}

This research was financially supported by the National Natural Science Foundation of China (nos. 51475165, 51165005, and 11462004) and the Natural Science Foundation of Jiangxi Province of China (no. 20151BAB206035).

\section{References}

[1] A. Muhammad, X. Yao, and Z. Deng, "Review of magnetorheological (MR) fluids and its applications in vibration control," Journal of Marine Science and Application, vol. 5, no. 3, pp. 1729, 2006.

[2] A. G. Olabi and A. Grunwald, "Design and application of magneto-rheological fluid," Materials \& Design, vol. 28, no. 10, pp. 2658-2664, 2007.

[3] A. Ashfak, A. Saheed, K. Rasheed A et al., "Design, fabrication and evaluation of MR damper," International Journal of Aerospace and Mechanical Engineering, vol. 1, pp. 27-33, 2011.

[4] X. Zhu, X. Jing, and L. Cheng, "Magnetorheological fluid dampers: a review on structure design and analysis," Journal of Intelligent Material Systems and Structures, vol. 23, no. 8, pp. 839-873, 2012.

[5] K. El Majdoub, D. Ghani, F. Giri, and F. Z. Chaoui, "Adaptive semi-active suspension of quarter-vehicle with magnetorheological damper," Journal of Dynamic Systems, Measurement, and Control, vol. 137, no. 2, Article ID 021010, 2015.

[6] Y. J. Shin, W. H. You, H. M. Hur, J. Park, and G. Lee, "Improvement of ride quality of railway vehicle by semiactive secondary suspension system on roller rig using magnetorheological damper," Advances in Mechanical Engineering, vol. 6, Article ID 298382, 2014.

[7] T. I. Ahamed, R. Sundarrajan, T. G. Prasaath, and V. Raviraj, "Implementation of magneto-rheological dampers in bumpers of automobiles for reducing impacts during accidents," Procedia Engineering, vol. 97, pp. 1220-1226, 2014.

[8] Z. C. Li and J. Wang, "A gun recoil system employing a magnetorheological fluid damper," Smart Materials and Structures, vol. 21, no. 10, Article ID 105003, 2012.

[9] H. J. Singh and N. M. Wereley, "Optimal control of gun recoil in direct fire using magnetorheological absorbers," Smart Materials and Structures, vol. 23, no. 5, Article ID 055009, 2014.

[10] E. Atabay and I. Ozkol, "Application of a magnetorheological damper modeled using the current-dependent Bouc-Wen model for shimmy suppression in a torsional nose landing gear with and without freeplay," Journal of Vibration and Control, vol. 20, no. 11, pp. 1622-1644, 2014.

[11] L. A. Powell, W. Hu, and N. M. Wereley, "Magnetorheological fluid composites synthesized for helicopter landing gear applications," Journal of Intelligent Material Systems and Structures, vol. 24, no. 9, pp. 1043-1048, 2013.

[12] J. Z. Chen and W. H. Liao, "Design, testing and control of a magnetorheological actuator for assistive knee braces," Smart Materials and Structures, vol. 19, no. 3, Article ID 035029, 2010.

[13] K. H. Gudmundsson, F. Jonsdottir, F. Thorsteinsson, and O. Gutfleisch, "An experimental investigation of unimodal and bimodal magnetorheological fluids with an application in prosthetic devices," Journal of Intelligent Material Systems and Structures, vol. 22, no. 6, pp. 539-549, 2011.

[14] Q. H. Nguyen, S. B. Choi, and J. K. Woo, "Optimal design of magnetorheological fluid-based dampers for front-loaded washing machines," Proceedings of the Institution of Mechanical Engineers, Part C: Journal of Mechanical Engineering Science, vol. 228, no. 2, pp. 294-306, 2014.

[15] Y. K. Lau and W. H. Liao, "Design and analysis of magnetorheological dampers for train suspension," Proceedings of the Institution of Mechanical Engineers Part F: Journal of Rail and Rapid Transit, vol. 219, no. 4, pp. 261-276, 2005.

[16] Z. J. Li, Y.-Q. Ni, H. Y. Dai, and S. Ye, "Viscoelastic plastic continuous physical model of a magnetorheological damper applied in the high speed train," Science China Technological Sciences, vol. 56, no. 10, pp. 2433-2446, 2013.

[17] S. Sun, H. Deng, W. Li et al., "Improving the critical speeds of high-speed trains using magnetorheological technology," Smart Materials and Structures, vol. 22, no. 11, Article ID 115012, 2013.

[18] G. Yang, B. F. Spencer Jr., H.-J. Jung, and J. D. Carlson, "Dynamic modeling of large-scale magnetorheological damper systems for civil engineering applications," Journal of Engineering Mechanics, vol. 130, no. 9, pp. 1107-1114, 2004.

[19] F. Amini and P. Ghaderi, "Optimal locations for MR dampers in civil structures using improved ant colony algorithm," Optimal Control Applications and Methods, vol. 33, no. 2, pp. 232-248, 2012.

[20] M. E. Uz and M. N. S. Hadi, "Optimal design of semi active control for adjacent buildings connected by MR damper based on integrated fuzzy logic and multi-objective genetic algorithm," Engineering Structures, vol. 69, pp. 135-148, 2014.

[21] B. Yang, J. Luo, and L. Dong, "Magnetic circuit FEM analysis and optimum design for MR damper," International Journal of Applied Electromagnetics and Mechanics, vol. 33, no. 1-2, pp. 207-216, 2010.

[22] J. Zheng, Z. Li, J. H. Koo, and J. Wang, "Magnetic circuit design and multiphysics analysis of a novel MR damper for applications under high velocity," Advances in Mechanical Engineering, vol. 6, Article ID 402501, 2014.

[23] H. H. Zhang, C. R. Liao, W. M. Chen, and S. L. Huang, "A magnetic design method of MR fluid dampers and FEM analysis on magnetic saturation," Journal of Intelligent Material Systems and Structures, vol. 17, no. 8-9, pp. 813-818, 2006.

[24] M. S. A. Khan, A. Suresh, and N. S. Ramaiah, "Analysis of magnetorheological fluid damper with various piston profiles," International Journal of Engineering and Advanced Technology, vol. 2, no. 2, pp. 77-83, 2012.

[25] M. M. Ferdaus, M. M. Rashid, M. H. Hasan, and M. A. Rahman, "Optimal design of Magneto-Rheological damper comparing different configurations by finite element analysis," Journal of 
Mechanical Science and Technology, vol. 28, no. 9, pp. 3667-3677, 2014.

[26] Z. Parlak, T. Engin, and İ. Çallı, "Optimal design of MR damper via finite element analyses of fluid dynamic and magnetic field," Mechatronics, vol. 22, no. 6, pp. 890-903, 2012.

[27] Q.-H. Nguyen and S.-B. Choi, "Optimal design of a vehicle magnetorheological damper considering the damping force and dynamic range," Smart Materials and Structures, vol. 18, no. 1, Article ID 015013, 2009.

[28] Z. Parlak, T. Engin, V. Ari, I. Şahin, and I. Çalli, “Geometrical optimisation of vehicle shock dampers with magnetorheological fluid," International Journal of Vehicle Design, vol. 54, no. 4, pp. 371-392, 2010.

[29] Z. Parlak, T. Engin, and I. Şahin, “Optimal magnetorheological damper configuration using the taguchi experimental design method," Journal of Mechanical Design, vol. 135, no. 8, Article ID 081008, 2013.

[30] J. Goldasz and B. Sapinski, "Verification of magnetorheological shock absorber models with various piston configurations," Journal of Intelligent Material Systems and Structures, vol. 24, no. 15, pp. 1846-1864, 2013.

[31] I. Ismail, S. A. Mazlan, H. Zamzuri, and A. G. Olabi, "Fluidparticle separation of magnetorheological fluid in squeeze mode," Japanese Journal of Applied Physics, vol. 51, no. 6, 2012.

[32] F. Imaduddin, S. A. Mazlan, M. A. Abdul Rahman, H. Zamzuri, Ubaidillah, and B. Ichwan, "A high performance magnetorheological valve with a meandering flow path," Smart Materials and Structures, vol. 23, no. 6, Article ID 065017, 2014. 


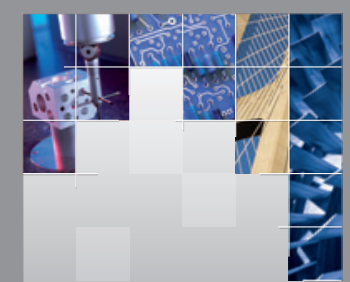

\section{Enfincering}
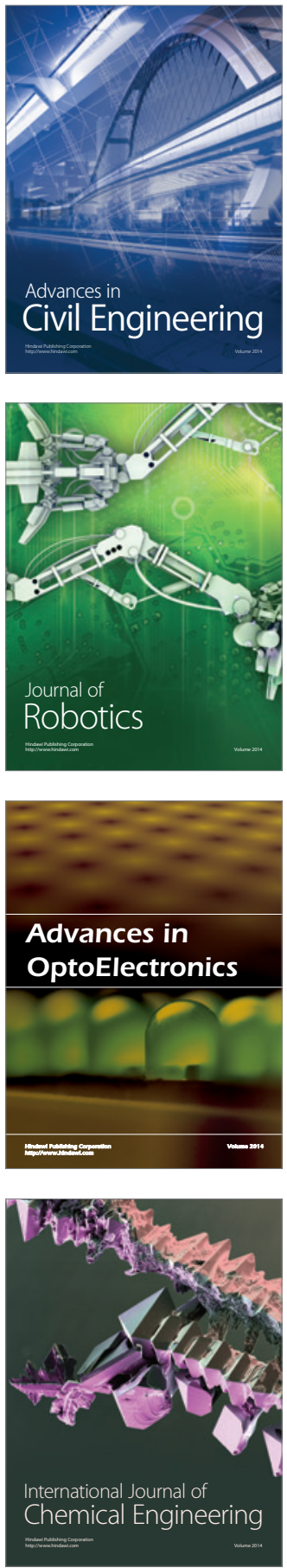

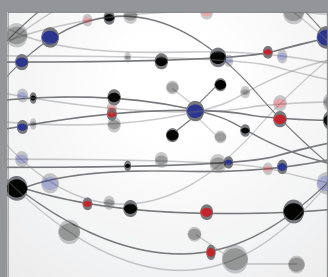

The Scientific World Journal

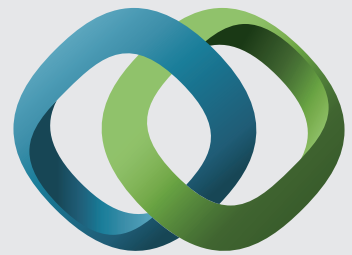

\section{Hindawi}

Submit your manuscripts at

http://www.hindawi.com
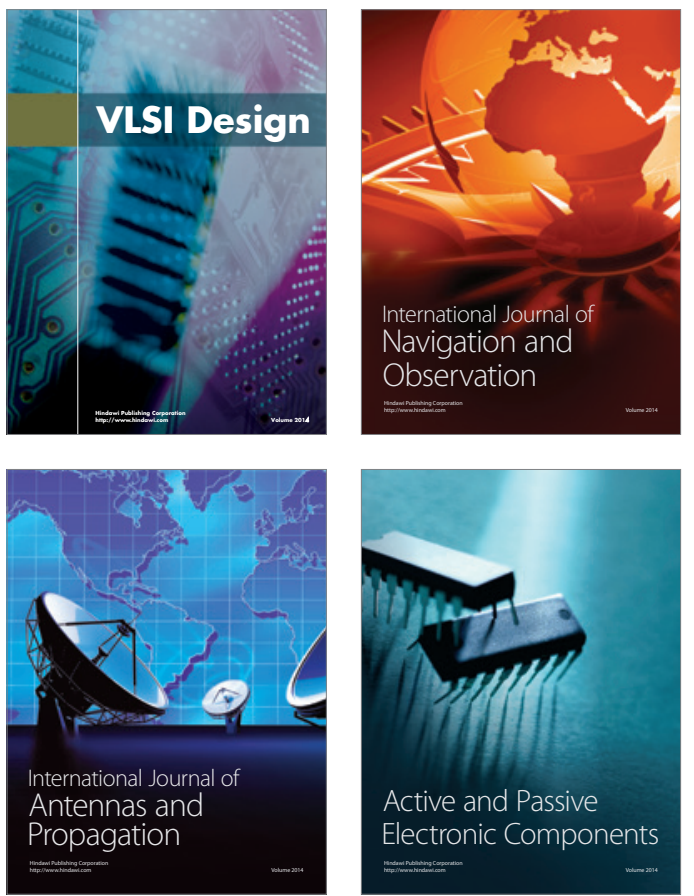
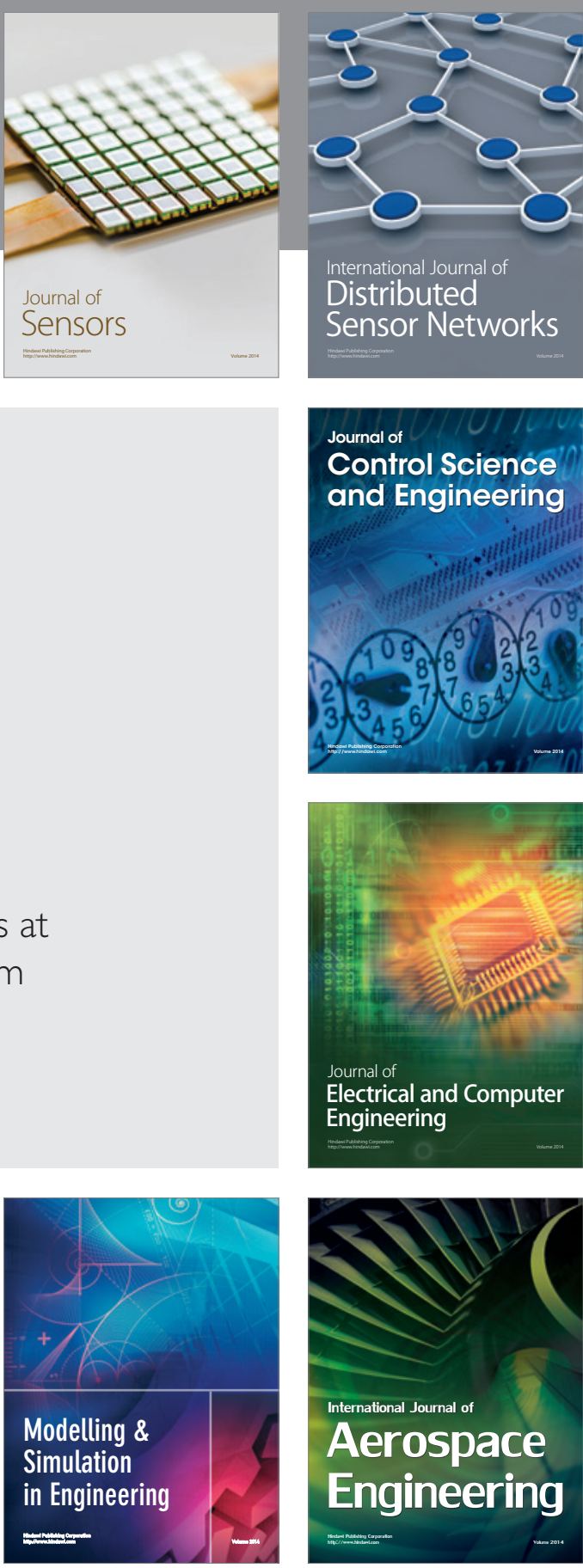

International Journal of

Distributed

Sensor Networks

Journal of

Control Science

and Engineering
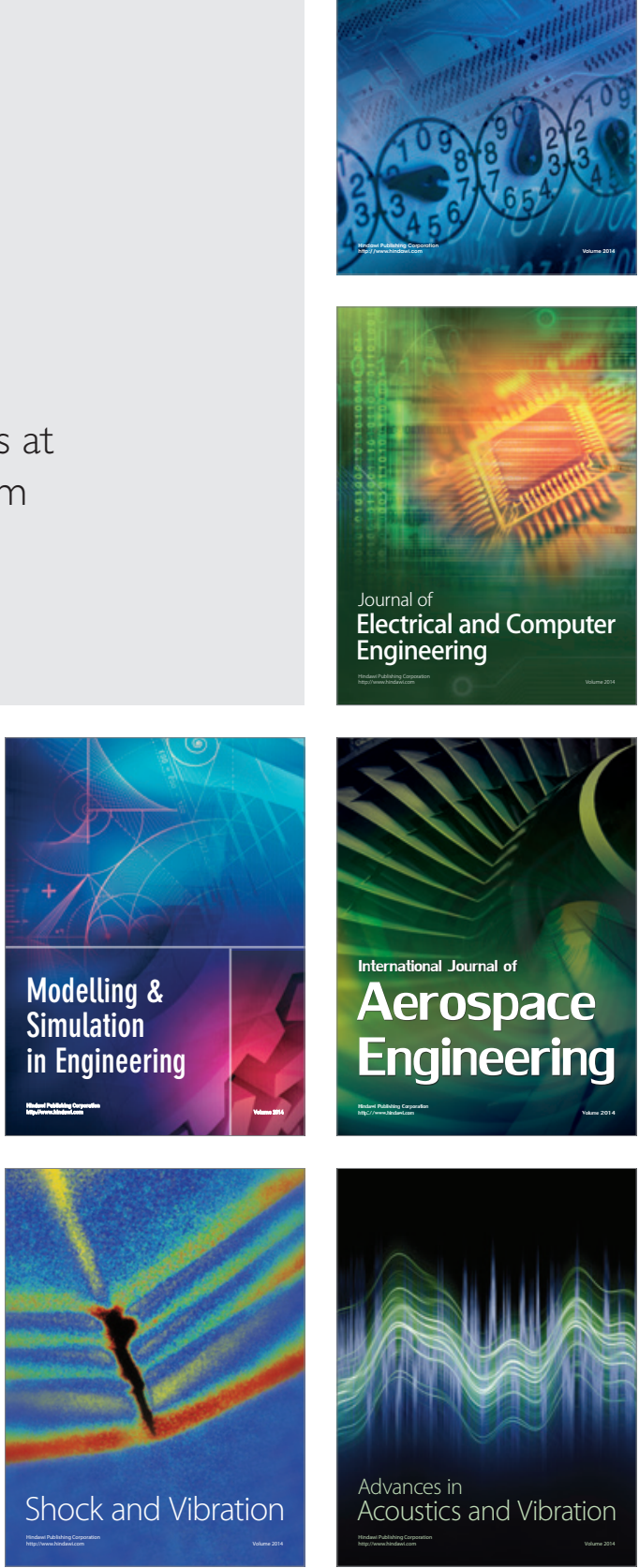